\title{
Diagnosis and clinical management of aortic dissection
}

This article was published in the following Dove Press journal:

Research Reports in Clinical Cardiology

19 June 2014

Number of times this article has been viewed

\author{
Phillips B Harrington \\ James E Davies \\ Spencer J Melby \\ Division of Cardiothoracic \\ Surgery, Department of Surgery, \\ University of Alabama at Birmingham, \\ Birmingham, AL, USA
}

\begin{abstract}
Aortic dissection is a potentially lethal clinical entity that requires rapid diagnosis, appropriate medical management, and potential surgical intervention. Nomenclature and treatments for aortic dissection are based on the location and extent of the dissection. Aortic dissections result from an intimal tear and may occur in the ascending aorta, aortic arch, or descending aorta. Patients with aortic dissection may present with a wide variety of symptoms secondary to the pattern of dissection and end organ malperfusion. Optimal medical therapy, often using a combination of medications to achieve systolic blood pressure control is essential in management of dissection. Surgical intervention is indicated for aortic dissection of the ascending aorta and aortic arch, and in selective dissections of the descending aorta. Regardless of operative technique, the goal of surgery is to prevent progression of the dissection, restore end organ perfusion whenever possible, and prevent rapid cardiovascular collapse and death.
\end{abstract}

Keywords: aorta, dissection, review, management, diagnosis

\section{Introduction}

Aortic dissection is a potentially deadly event in which blood exits the normal aortic lumen and dissects down the tunica media, creating a false lumen. This process can result in rapid cardiovascular collapse and sudden death, or in a vast array of end organ malperfusion states. While aortic dissection has a wide variety of presenting symptoms, clinicians must remain vigilant to avoid missing this potentially lethal but treatable disorder. This paper reviews the etiology, classification, presentation, diagnosis, and clinical management of aortic dissection.

\section{Etiology/classification}

A number of risk factors have been identified for development of aortic dissection, most of which relate to structural defects in the aortic media. Medial degeneration (cystic medial necrosis) of the aorta greater than expected for age is present in about $20 \%$ of patients. ${ }^{1,2}$ Marfan syndrome, with its inherited defect in fibrillin, an important component of the elastic tissue in the aortic media, carries a $20 \%-40 \%$ lifetime risk of dissection. ${ }^{3}$ Other genetic connective tissue diseases such as the Turner, Noonan, EhlersDanlos, and Loeys-Dietz syndromes carry an associated higher risk. Any structural defect in the aorta (annulo-aortic ectasia, dilated ascending aorta ${ }^{2}$ aortic coarctation, ${ }^{4}$ or bicuspid aortic valve ${ }^{5}$ ) may increase the risk of dissection. Mechanical disruption of the aorta either by blunt chest trauma ${ }^{6}$ or an iatrogenic source, such as aortic cannulation for cardiopulmonary bypass, manipulation with wires during cardiac catheterization, or aortic cross-clamping, may create a dissection point. ${ }^{7}$ Aortic dissection may occur
Correspondence: Spencer J Melby

Division of Cardiothoracic Surgery, Department of Surgery, University of Alabama at Birmingham,

THT 720, 1720 2nd Ave S,

Birmingham AL 35294-0006, USA

Tel +l 2059967019

Fax +l 2059345486

Email smelby@uabmc.edu 
during pregnancy in healthy patients or those with a known history of Marfan syndrome. It occurs later in pregnancy for non-Marfan patients ( $100 \%$ in the third trimester) with more variable timing in women with Marfan syndrome (46.8\% in the third trimester $)^{8}$ and may be met with fatal consequence for mother and fetus if unrecognized as a source of maternal cardiovascular collapse..$^{9-12}$

Intimal tear as the primary etiology of aortic dissection in the majority of cases is supported by numerous studies and post mortem reviews, including the series reported by Larson et al which identified an intimal tear in all 161 patients autopsied after aortic dissection., ${ }^{2,9}$ The point of entry for blood into the aortic media is usually through an intimal tear or via rupture of the aortic vasa vasorum. ${ }^{10,11}$ The latter is supported by the finding of an intramural aortic hematoma and intraoperative or post mortem observation that failed to identify an intimal tear. Dissection commonly begins in the ascending aorta and may extend through the arch and into the descending aorta. ${ }^{2}$ Dissections that originate in the aortic arch (approximately 10\% of cases) may extend proximally into the ascending aorta or distally to the descending aorta. ${ }^{12}$ Descending aortic dissections usually extend distally, but retrograde extension back into the arch has been observed in up to $38 \%$ of patients, as well as extension into the proximal ascending aorta. ${ }^{2}$

As the aortic dissection propagates through the aortic media it creates a false lumen separated from the true aortic lumen by a thin internal membrane. ${ }^{6}$ This process may extend to any of the branches of the aorta or down to the iliac arteries, and may involve the coronary vessels which can precipitate malperfusion or myocardial infarction. Branch vessels may shear off the true lumen creating fenestrations that allow blood to communicate between the false and true lumen. Aortic branches may become occluded by the dissecting intima and media, dissect off the true lumen to be perfused only by the false lumen, or remain uninvolved. This variable pattern of dissection accounts for the wide variety of clinical presentations of aortic dissection. In the acute setting, the false lumen may only be contained by a thin wall of aortic adventitia. Ascending aortic dissection may lead to mediastinal or pericardial hematoma with potential rupture, while in a descending thoracic or abdominal aortic dissection, rupture can lead to hemothorax or uncommonly retroperitoneal hemorrhage. If acute aortic rupture does not occur, the false lumen may enlarge over time and become aneurysmal in nature, eventually leading to thrombosis or rupture into the pericardium, the pleural space (usually left), or less commonly the abdomen.

The DeBakey ${ }^{13}$ and Stanford ${ }^{14}$ classifications are commonly used to describe aortic dissection (Figure 1). Stanford type A includes all dissections in which the ascending aorta is involved, and in type B only the descending aorta is involved. This classification system is useful as it distinguishes between cases which need urgent surgical intervention (type A) and those which can typically be managed medically (type B). The DeBakey classification uses both the origin and the extent of the dissection, which can alter management strategies. DeBakey type I dissections originate in the ascending aorta and extend into the descending aorta. Type II dissections also originate in the ascending aorta, but are contained there and do not extend to the descending aorta. Type III dissections originate in the descending aorta (usually just distal to the left subclavian artery) and are confined to the descending aorta (type IIIa), or may extend into the distal abdominal aorta or proximally back into the aortic arch (type IIIb).

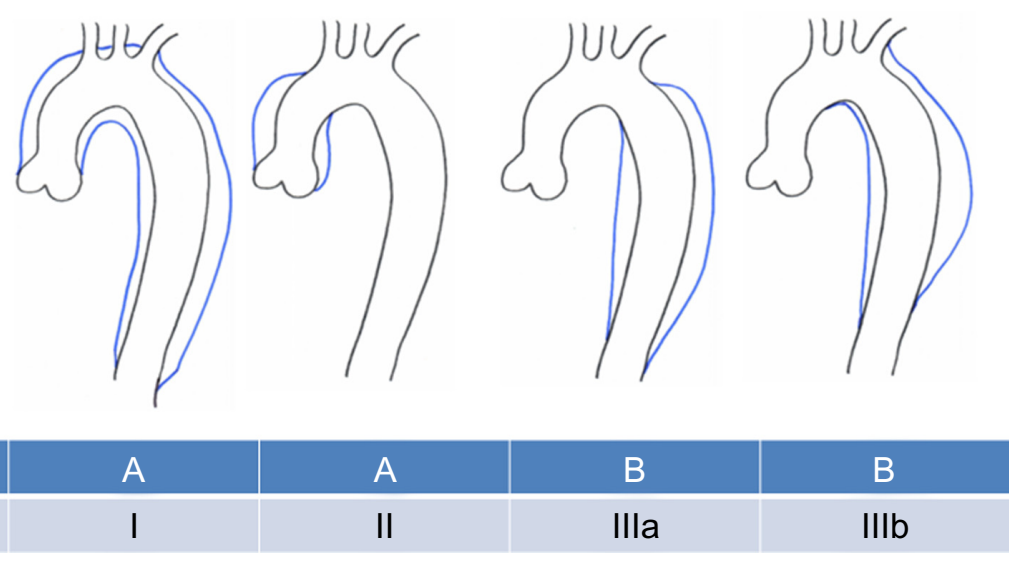

Figure I DeBakey and Stanford classification systems for aortic dissections. Note the DeBakey system distinguishes between dissections of the ascending aorta that extend into the aortic arch and those that do not. The Stanford system makes no such distinction. 
Classically, acute aortic dissections are those in which the dissection has been present and ongoing for less than 14 days, and those older than 2 weeks are termed chronic. However, clinicians must distinguish between true acute dissection and "subacute" dissections (those more than 24 hours after presentation but not yet at 2 weeks), which may be stabilized prior to surgery. True acute type A dissections carry a high mortality $(30 \%-50 \%$ in the first 24 hours including the prehospital setting and then $1 \%$ per hour afterward) and therefore are treated as true surgical emergencies..$^{15,16}$

\section{Presentation/diagnosis}

Arterial hypertension is present in $80 \%-90 \%$ of patients presenting with acute aortic dissection, and vasoconstrictive drugs such as cocaine also appear to increase risk. ${ }^{17}$ In a 30-year series of aortic dissections, Fann et al showed that ascending dissections occurred in patients with a mean age of $56 \pm 14$ (range 15-85) years and descending aortic dissection in slightly older patients with a mean age of $64 \pm 13$ (range 32-86) years. ${ }^{18}$ A history of connective tissue disorders, specifically Marfan syndrome, should raise suspicion of aortic dissection. While some patients may remain asymptomatic, the majority of those with a type A dissection will present with acute chest pain. Pain may radiate into the arms or neck and be confused with angina pectoris. As the dissection progresses, symptoms from aortic branch occlusions may present as stroke (5\%-10\% type $\left.\mathrm{I}^{19}\right)$, paraplegia, oliguria/anuria, abdominal pain, nausea/vomiting, or a pulseless limb. ${ }^{20}$

Aortic dissection on plain chest radiography may demonstrate a widened mediastinum, particularly for type I and II dissections. Cardiomegaly may be seen from pericardial effusion, and a pleural effusion or hemothorax particularly on the left side may be present. Transthoracic echocardiography is a useful tool in critically ill patients to aid in rapid evaluation of a type A dissection, but a transesophageal echogram allows for a more accurate diagnosis. Echocardiography has been shown to be highly sensitive and specific for identifying type A aortic dissection ${ }^{21}$ and can also identify pericardial fluid, evidence of cardiac tamponade, aortic valve dysfunction, involvement of coronary arteries, and abnormal ventricular wall motion. ${ }^{22}$ However, evaluation of the distal ascending aorta, aortic arch, and descending aorta is limited with this modality due to limitations in the ability of the echo probe to visualize those more posterior anatomic structures. Transesophageal echography is more invasive than other studies for this disease.

Computed tomography (CT) with intravenous contrast is widely available in most emergency departments and produces high quality images useful in diagnosis of aortic dissection. ${ }^{23}$ Sensitivity with modern helical CT scanning approaches $100 \%$ and specificity is $98 \% .{ }^{24}$ It gives important information about the thoracic cavities and may be carried down into the abdomen to reveal abdominal aortic pathology. CT is not without disadvantages, ie, it gives no information about the function of the heart or its valves, and requires the use of intravenous contrast (which may provoke allergy or cause renal impairment).

The use of magnetic resonance imaging (MRI) with or without gadolinium (magnetic resonance angiography) can also provide excellent images useful in the diagnosis of aortic dissection (Figure 2). ${ }^{24}$ It may identify the sites of entry between true and false lumens and thrombus location. Use of MRI may be limited by accessibility and the longer time needed to complete the study compared with CT or transthoracic echocardiography.

Aortic angiography remains a highly sensitive and specific diagnostic tool that may be employed as part of an endovascular or interventional procedure. ${ }^{22}$ It is able to assess branch vessels and give important information about aortic valve and ventricular function. Major disadvantages are the need for arterial access, the use of wires and sheathed catheters inserted into the aorta (which may further damage friable and torn intima), and allergy/renal injury from use of intravenous contrast. There is also a potential false negative if one aortic lumen is thrombosed. The speed and less

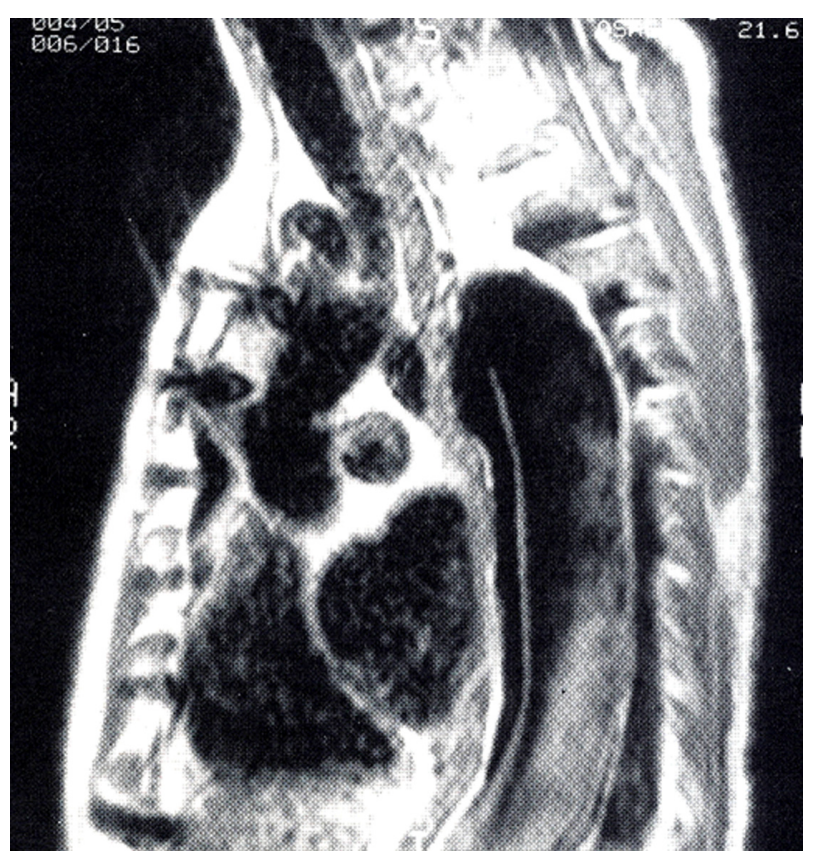

Figure 2 Magnetic resonance angiogram image of an acute type B aortic dissection Note the intimal flap on the anterior aorta. 
invasive nature of echo, CT, and MRI has led many centers to no longer routinely obtain aortic angiograms in cases of aortic dissection.

The use of coronary angiography remains controversial and is not recommended due to potential delay in operative management and added contrast dye load. It has been used to diagnose and treat significant coronary atherosclerotic stenosis with a simultaneous coronary artery bypass grafting at the time of dissection repair in hemodynamically stable patients without pericardial effusion. ${ }^{25}$ However, delay in diagnosis and treatment of the dissection may increase the risk of rupture and subsequent death in patients with acute dissection. ${ }^{26}$ In cases of missed dissection, the use of angiography during percutaneous coronary intervention with use of thrombolytic agents and antiplatelet drugs can have catastrophic consequences by converting a contained rupture into a free one, and thus is not recommended.

Patients with previous cardiac surgery present challenges in diagnosis and management of their aortic dissection. In one study, previous cardiac surgery was an independent risk factor for increased length of hospital stay and intermediate mortality. This increased risk was likely due to delay in presentation and diagnosis, and increased medical management. ${ }^{27}$ In a few select patients with previous aortic suture lines, surgery may be delayed because the risk of cardiac tamponade is minimized due to adhesions from prior surgery and in cases where the dissection originates distal to a previous suture line the proximal progression (and subsequent risk of coronary and valve involvement) is halted by the previous suture line. ${ }^{28}$

\section{Management Stanford type A and DeBakey type I/II dissections}

For aortic dissections involving the ascending aorta (Stanford type A/DeBakey types I and II), surgical repair is the primary method of management. Based on the natural history of ascending dissections and the potentially fatal consequences of aortic rupture or cardiac tamponade, urgent repair is indicated in the majority of cases. ${ }^{29}$ The danger of this dissection is propagation to the aortic root, which can result in four life-threatening sequelae, ie, acute aortic insufficiency, acute myocardial infarction, rupture into the pericardial space and subsequent cardiac tamponade, and/or rupture of the aorta at any point, resulting in rapid exsanguination. Extreme age, poor performance status, end stage dementia, incurable malignancy, and irreversible brain injury are all relative contraindications for operative repair. Evolving stroke, new paraplegia, renal injury, extremity ischemia, or other signs of branch vessel involvement are not considered contraindications to proceed with surgical repair. In fact, symptoms of branch vessel involvement may improve or resolve after repair. ${ }^{28}$ The goals of surgical repair are to first prevent potentially fatal consequences of proximal propagation, second to remove the site of intimal tear, and finally to restore normal aortic and branch vessel blood flow if surgically feasible.

Although surgical repair is the mainstay of treatment, there are a number of important medical considerations prior to operation that should begin once the diagnosis of aortic dissection is made, or if surgical repair is delayed or not indicated. Preparation for surgical intervention may include transfer to an appropriate medical center with experience in management of aortic dissection. Patients should be closely observed in a monitored setting where continuous invasive arterial blood pressure is followed. Blood pressures should be checked in multiple extremities to evaluate for variability due to branch vessel malperfusion. Systemic arterial blood pressure control combined with reduction in the contractile force of the myocardium, expressed as the change in pressure over time $(\mathrm{dP} / \mathrm{dt})$ often with multiple drug therapy, is an important component of preoperative care. ${ }^{30}$ The term "anti-impulse therapy" has been used to describe this strategy and is designed to reduce further propagation of the aortic dissection. To this end, first-line treatment should include use of beta adrenergic blockers such as propranolol or esmolol to reduce systemic blood pressure to less than 120 $\mathrm{mmHg}$ systolic and heart rate to 60-70 beats per minute. These drugs will also reduce sympathetic flow to the heart and vasculature. Addition of a systemic vasodilator, such as nitroprusside, to further reduce arterial blood pressure may be needed, but should not be used in isolation due to potential reflex tachycardia from the reduction in mean arterial pressure, which may increase cardiac contractility, increase $\mathrm{dp} / \mathrm{dt}$, and propagate the dissection. ${ }^{28}$ Goal systolic blood pressure is $100-120 \mathrm{mmHg}$, with mean arterial pressures of $60-75 \mathrm{mmHg}$. Patients should be adequately volumeresuscitated, especially in the setting of hypotension. Other important medical considerations include the appropriate use of analgesics and anxiolytics to reduce the patient's pain and discomfort which may contribute to hypertension and tachycardia.

Surgical repair of ascending aortic dissection will involve the use of cardiopulmonary bypass and systemic heparinization with a variety of cannulation strategies and possibly systemic hypothermic circulatory arrest. Common setups include femoral or axillary arterial cannulation and vena cava 
cannulation via the right atrium or bicaval cannulation via the superior and inferior vena cava. Once the patient is successfully placed on cardiopulmonary bypass with adequate flow, the patient's core body temperature is lowered to the desired levels.

The operative approach varies among surgeons, but all approaches have the same goals, ie, to repair the aorta, prevent the lethal consequences of proximal progression, evaluate and manage any arch vessel involvement, and reduce the risk of distal propagation. The accepted standard technique uses hypothermic circulatory arrest with core body temperatures as low as $18^{\circ} \mathrm{C}-20^{\circ} \mathrm{C}$ and performs the distal anastomosis without placing a clamp on the aorta for cases in which visualization and possible arch repair are necessary. Another approach to treating acute type I and II aortic dissection entails cross-clamping the aorta at the level of the innominate artery, opening the aorta, and repair of the proximal and distal ascending aortic pathology. ${ }^{31}$ The merits of the different techniques (ie, mortality and complication rates) have been analyzed and debated by the surgical community. In a large study at Barnes-Jewish Hospital (St Louis, MO, USA), operative technique was not implicated in patient outcomes. ${ }^{31,32}$ If hypothermic circulatory arrest is planned for longer than 15-20 minutes, the patient's head is packed in ice. An adjunct to hypothermic circulatory arrest introduced in the mid 1990s is the use of retrograde cerebral perfusion. In this technique, cold oxygenated blood is infused via the superior vena cava into the cerebral circulation. ${ }^{33,34}$ Studies suggest the benefits of retrograde cerebral perfusion as an adjunct may be from the enhanced cranial hypothermia ${ }^{35}$ and may prevent embolic events by retrograde flushing of the cerebral arterial circulation. ${ }^{36}$ More recently, infusion of cold oxygenated blood via the axillary artery, known as antegrade cerebral perfusion, has been used for additional cerebral protection. ${ }^{37}$ Surgeons employ cross clamping, hypothermic circulatory arrest with or without retrograde cerebral perfusion/antegrade cerebral perfusion based on preference, and then use preoperative and intraoperative findings for operative guidance to best achieve good outcomes.

Regardless of cannulation and a cerebral protection strategy, replacement of the ascending aorta with a synthetic tube graft including the location of the intimal tear is the mainstay of treatment. The aorta is opened longitudinally and inspected for the location of the intimal tear. The use of polytetrafluoroethylene felt, or pericardial strips sutured inside and/or outside the proximal and distal lumens of the aorta, aid in reinforcing the dissected aortic wall. The use of biological glues may augment this process to aid in sealing the repair (Figure 3). The graft is sutured to the distal aortic cuff with a running polypropylene suture, often with felt reinforcement on the intimal, medial, and/or adventitial layers to support the fragile tissue. If antegrade cerebral perfusion is not being employed and the distal anastomosis is complete, a clamp may be placed on the graft (or alternately a graft with a prefabricated sidearm may be used) and a cardiopulmonary bypass cannula inserted to re-establish antegrade aortic perfusion to the brain and branch vessels. The proximal suture line is completed in a similar fashion, the aorta and heart are de-aired, and the patient is rewarmed and then weaned from cardiopulmonary bypass. If the aortic arch is included in the repair, an elliptical incision can be made around the origins of the brachiocephalic and left subclavian arteries, creating an aortic island that is sutured to the tube graft after completion of the distal anastomosis. For isolated ascending aortic dissections (DeBakey type II), primary repair of the aorta with an end to end anastomosis after resection of the aortic segment containing the intimal tear can be done. ${ }^{38}$

During surgical correction of type I and II dissections, surgeons must consider the need for concomitant aortic valve

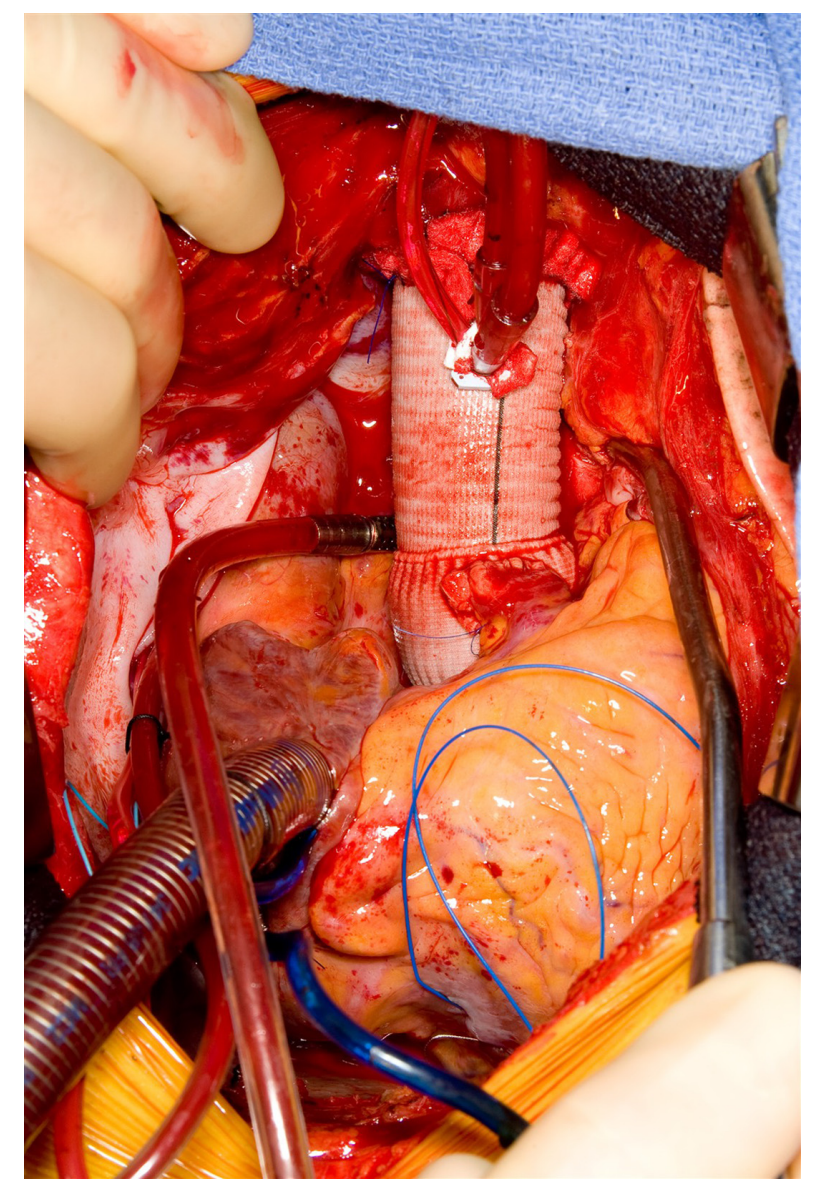

Figure 3 Completed open repair of type A aortic dissection. 
and/or aortic root replacement. Preoperative and intraoperative transesophageal echography will indicate the extent of aortic regurgitation and need for intervention. In the absence of intrinsic valve pathology, the majority of cases resuspension of the aortic valve commissures after dissection repair is adequate, even with severe preoperative aortic valve insufficiency. In cases of aortic leaflet pathology, a valve replacement may be indicated. If the aortic root is significantly dilated and ectatic, it may cause aortic valve dysfunction and thus require replacement. Commonly this is done with a composite graft containing a pre-sewn valve. ${ }^{39}$ Aortic root allographs may be used in the elderly or in patients with contraindications to long-term anticoagulation. ${ }^{40}$

If the coronary arteries are involved with the dissection, they may be repaired or bypassed. In cases where the ostia of the coronary arteries are involved, these may be removed as part of a root replacement and primarily reattached to the tube graft or bypassed with interposition vein grafts. Involvement of the coronary arteries represents an additional surgical challenge which carries increased hospital mortality. $^{41}$

Large type I dissections that extend well into the descending thoracic aorta may require additional surgical consideration. Total arch replacement has been performed at experienced centers to address the potential for later aneurysmal dilation of the distal false lumen, encourage thrombosis of the false lumen, and prevent distal aortic dissection. ${ }^{42}$ An alternative method to total arch replacement is placement of a distal tube graft deployed down the open distal aorta at the time of open repair of the aortic arch. ${ }^{43}$ This "elephant trunk" approach may be performed with a traditional open tube graft sutured to the proximal thoracic aorta or more recently through the use of an endovascular stent graft deployed distally down the open lumen of the proximal descending aorta. ${ }^{44}$

Unfortunately, despite advanced medical and surgical care, mortality for aortic dissection remains high. The International Registry of Acute Aortic Dissection (IRAD) series of over 500 patients showed an in-hospital mortality of $25.1 \%$ from 1996 to 2001 for patients with acute type A dissection. Independent preoperative predictors of operative mortality were history of aortic valve replacement, migrating chest pain, hypotension as sign of acute type A aortic dissection, shock or tamponade, preoperative cardiac tamponade, and preoperative limb ischemia. ${ }^{45}$ Long-term survival as tracked by the Stanford group showed that survival at one, 5,10 , and 15 years was $67 \%, 55 \%, 37 \%$, and $24 \%$, respectively. ${ }^{18}$

\section{DeBakey type III/type B dissections}

Management of patients presenting with aortic dissections originating in the descending aorta (type B/DeBakey type III) is based on a number of factors. If patients have no evidence of branch vessel malperfusion, medical management is indicated. A study comparing medical versus surgical management in uncomplicated type III patients showed no difference in mortality. ${ }^{46}$

Similar to the preoperative medical therapy for type I and type II dissections, medical therapy for type III dissections is targeted to reduce systemic arterial blood pressure, reduce left ventricular output (limiting dP/dt, or "anti-impulse therapy"), and maintain end organ profusion. Acute management with vasodilators and beta blockers should be employed with invasive blood pressure monitoring in an intensive setting. Longer term medical therapy for type III dissections also includes use of angiotensin-converting enzyme inhibitors, which have been shown to reduce long-term aortic events, ${ }^{47}$ and angiotensin II receptor blockers, a new class of drug with potential to further aid in medical management. Recent evidence also indicates that use of a metalloproteinase inhibitor (doxycycline) and statins may play a role in minimizing the progression of dissection. ${ }^{48}$

In the acute setting, evidence of malperfusion (paraplegia, limb ischemia, renal impairment, mesenteric ischemia) or hemodynamic instability are indications for consideration of urgent surgical intervention. For chronic type III dissections, indications for surgical repair include: refractory hypertension (continued hypertension despite a three-drug regimen and expert management); increase in aortic size on follow-up CT scans ( $>0.5 \mathrm{~cm}$ increase per year); continued aneurysmal dilation with increasing risk for rupture (diameter $\geq 6.5 \mathrm{~cm}^{49}$ ); worsening malperfusion of aortic branch vessels; and continued or worsening pain. ${ }^{50}$

Classically, repair of a type III aortic dissection is performed through a left posterior thoracotomy with the patient in the lateral decubitus position. Depending on the extent of aortic reconstruction and expected length of aortic clamping, cardiopulmonary bypass may be employed via left atrial-femoral vein or femoral-femoral cannulation. If the distal aortic arch is included in the replacement, full cardiopulmonary bypass with or without hypothermic circulatory arrest may be utilized. During the repair, distal aortic profusion may be employed to minimize ischemia to the distal aortic branches.

Surgical replacement of the distal aorta is performed in similar fashion to type I or type II dissections. The proximal aorta is mobilized to expose the dissection with care 
to identify and protect the vagus nerve with its recurrent laryngeal branch and the esophagus. Proximal control can be obtained with a clamp placed between the left carotid and left subclavian arteries. The aorta is entered longitudinally and the intimal tear identified. Polytetrafluoroethylene felt strips and/or biological glue are placed on the proximal and distal aortic lumens to buttress the dissected intima to the adventitia. A tube graft is sutured in place to restore normal anatomical aortic flow and exclude the false lumen. In cases that involve multiple lumbar arteries, they may be reimplanted individually or by reimplantation of an aortic cuff containing the lumbar artery origins, or oversewn when they have brisk back-bleeding.

Recent advances in endovascular surgical techniques have led many centers to now repair type III dissections with a thoracic endovascular stent graft (TEVAR, Figure 4). ${ }^{51}$ Arterial access via the femoral arteries is obtained, sheaths are inserted, and the stent graft is deployed proximal to the intimal tear with the aim to exclude and depressurize the false lumen and restore adequate flow through the true aortic lumen. ${ }^{52}$ TEVAR has been shown to be safe and effective with acceptable outcomes, with the added advantage of avoiding the morbidity of a large thoracotomy. ${ }^{53}$ Need for reintervention $(4.6 \%-47 \%)$, paraplegia $(0.8 \%-9.4 \%)$, stroke $(0 \%-11 \%)$, and stent graft migration or collapse are some of the complications that can occur with TEVAR. In the early experience, reports have indicated that acute dissections repaired with TEVAR carry a higher risk for poor outcomes compared with chronic dissections. ${ }^{52}$

Mortality for type B dissections varies given the variety of management strategies. A 2006 study from IRAD reported an overall in-hospital mortality of $29.3 \%$ for acute type B dissections refractory to medical therapy treated surgically, with independent predictors of surgical mortality being age $>70$ years and preoperative shock/hypotension. ${ }^{54}$ More recent IRAD data including TEVAR appear to show

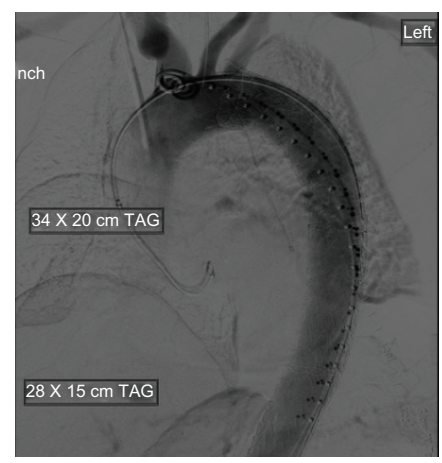

Figure 4 Intraoperative aortogram during endovascular repair of type B dissection. Abbreviation: TAG, thoracic aorta graft. improving mortality with endovascular therapy, with an in-hospital mortality of $10.9 \%$ and $8.1 \%$ for patients discharged alive at one year. ${ }^{55}$ Comparison with surgically treated historical controls is difficult, however, because patient characteristics are not similar when compared to the expanded criteria used in determining intervention with TEVAR. Goal-directed "anti-impulse" medical therapy for type B dissections appears to have an in-hospital mortality of $8.8 \%$, with rupture being the only independent risk factor by multiple logistic regression analysis. ${ }^{56}$

\section{Follow-up and surveillance of chronic dissection}

Patients with aortic dissection should be followed closely regardless of whether they require surgical repair or are medically managed. Hallmarks of follow-up care are centered around risk reduction of future or continued dissection and radiographic surveillance for further aortic disease. Continued control of systemic blood pressure is essential and may be managed with a variety of medical therapies. In particular, long-term beta blockade has been suggested to reduce the risk of reoperation..$^{57}$ In patients with Marfan syndrome, beta blockade has also been shown to reduce the rate of aortic dilation and risk of dissection. ${ }^{58} \mathrm{~A}$ common surveillance protocol proposed by Borst et al includes an intravenous contrast enhanced CT scan prior to discharge, one at 3 and 9 months, and then spaced to 12-month intervals for aortas $\geq 5 \mathrm{~cm}$ or 24 months for aortas $<5 \mathrm{~cm} .{ }^{59}$ Patients are at risk for aneurysmal dilation of other portions of the native aorta or degeneration of the suture line. Patients who underwent a valve replacement or repair should undergo transesophageal echography prior to discharge, and at 3 and 9 months, and if persistent aortic regurgitation is present, transesophageal echography yearly after that (Table 1). ${ }^{59}$ For type B dissections, recurrence of symptoms, aortic aneurysmal dilation $(>5.5 \mathrm{~cm})$, or a yearly increase $>4 \mathrm{~mm}$ after the acute phase are predictors of adverse outcome and need for delayed aortic repair. ${ }^{50}$

Unfortunately, the need for reoperation after repair of aortic dissection remains high. The Stanford series reported a 17\% (confidence limit 14\%-20\%) need for reoperation after repair of acute type A dissections. ${ }^{18}$ Risk factors for reoperation include young age, patients with Marfan syndrome, and severe preoperative aortic regurgitation. ${ }^{60,61}$ Other risk factors include, male sex, elevated systolic blood pressure, failure to resect the proximal tear, a patent false lumen, large aortic diameter, and absence of beta blocker therapy. ${ }^{57,60,62}$ 
Table I Surveillance schedule after acute aortic dissection

\begin{tabular}{|c|c|c|}
\hline Time of study & Study & Indication \\
\hline Before hospital & $\mathrm{CT}$ or $\mathrm{MRI}$ & All patients \\
\hline \multirow[t]{2}{*}{ discharge } & TTE & Valve reconstruction \\
\hline & Arteriography & $\begin{array}{l}\text { Suspected or clinic evident } \\
\text { malperfusion }\end{array}$ \\
\hline \multicolumn{3}{|l|}{ After discharge } \\
\hline \multirow[t]{2}{*}{3 months } & $\mathrm{CT}$ or $\mathrm{MRI}$ & Residual dissection or dilated aorta \\
\hline & TTE & Valve reconstruction \\
\hline \multirow[t]{2}{*}{9 months } & $\mathrm{CT}$ or $\mathrm{MRI}$ & Residual dissection or dilated aorta \\
\hline & TTE & Valve reconstruction \\
\hline \multicolumn{3}{|l|}{ Follow-up } \\
\hline \multirow[t]{3}{*}{ Every 6 months } & CT or MRI & Progression of aortic disease, \\
\hline & & Marfan syndrome \\
\hline & TTE & Aortic regurgitation \\
\hline Every 12 months & CT or MRI & Aortic diameter $\geq 5 \mathrm{~cm}$ \\
\hline Every 24 months & CT or MRI & Aortic diameter $<5 \mathrm{~cm}$ \\
\hline
\end{tabular}

Note: Modified from Borst et al. Surgical Treatment of Aortic Dissection. Churchill Livingstone; 1996..99 Copyright (C) 1996 British Journal of Surgery Society Ltd. Abbreviations: CT, computed tomography scan; MRI, magnetic resonance image; TTE, transthoracic echocardiogram.

\section{Future challenges and treatments}

The management of aortic dissection will continue to evolve as researchers attempt to identify which subset of patients will benefit maximally from which therapy. There are ongoing studies looking at TEVAR versus medical management for uncomplicated type B/type III dissections, eg, the INSTEAD (INvestigation of STEnt Grafts in Aortic Dissection) trial. ${ }^{63}$ Further use of endovascular techniques with branched devices for type I and II dissections has been and will continue to be explored.

\section{Conclusion}

Aortic dissection remains a challenging disease process that requires clinical vigilance, rapid diagnosis, and goal-directed management. Despite best medical therapy and advances in surgical technique, aortic dissection continues to carry a high morbidity and mortality. Clinicians must understand the pathophysiology of aortic dissection and appropriate management strategies for both type A and type B dissections.

\section{Disclosure}

The authors report no conflicts of interest in this work.

\section{References}

1. Schlatmann TJ, Becker AE. Pathogenesis of dissecting aneurysm of aorta. Comparative histopathologic study of significance of medial changes. Am J Cardiol. 1977;39(1):21-26.

2. Larson EW, Edwards WD. Risk factors for aortic dissection: a necropsy study of 161 cases. Am J Cardiol. 1984;53(6):849-855.

3. Roberts WC, Honig HS. The spectrum of cardiovascular disease in the Marfan syndrome: a clinico-morphologic study of 18 necropsy patients and comparison to 151 previously reported necropsy patients. Am Heart J. 1982;104(1):115-135.
4. Hirst AE Jr, Johns, VJ Jr, Kime SW Jr. Dissecting aneurysm of the aorta: a review of 505 cases. Medicine (Baltimore). 1958;37(3):217-279.

5. Edwards WD, Leaf DS, Edwards JE. Dissecting aortic aneurysm associated with congenital bicuspid aortic valve. Circulation. 1978; 57(5):1022-1025.

6. Roberts WC. Aortic dissection: anatomy, consequences, and causes. Am Heart J. 1981;101(2):195-214.

7. Gott JP, Cohen CL, Jones EL. Management of ascending aortic dissections and aneurysms early and late following cardiac operations. J Card Surg. 1990;5(1):2-13.

8. Yuan SM. Aortic dissection during pregnancy: a difficult clinical scenario. Clin Cardiol. 2013;36(10):576-584.

9. Murray CA, Edwards JE. Spontaneous laceration of ascending aorta. Circulation. 1973;47(4):848-858.

10. Gore I. Pathogenesis of dissecting aneurysm of the aorta. AMA Arch Pathol. 1952;53(2):142-153.

11. DeSanctis RW, Doroghazi RM, Austen WG, Buckley MJ. Aortic dissection. N Engl J Med. 1987;317(17):1060-1067.

12. Okita Y, Takamoto S, Ando M, et al. Surgery for aortic dissection with intimal tear in the transverse aortic arch. Eur J Cardiothorac Surg. 1996;10(9):784-790.

13. DeBakey ME, McCollum CH, Crawford ES, et al. Dissection and dissecting aneurysms of the aorta: twenty-year follow-up of five hundred twenty-seven patients treated surgically. Surgery. 1982;92(6): 1118-1134.

14. Daily PO, Trueblood HW, Stinson EB, Wuerflein RD, Shumway NE. Management of acute aortic dissections. Ann Thorac Surg. 1970;10(3): 237-247.

15. Olsson C, Thelin S, Ståhle E, Ekbom A, Granath F. Thoracic aortic aneurysm and dissection: increasing prevalence and improved outcomes reported in a nationwide population-based study of more than 14,000 cases from 1987 to 2002. Circulation. 2006;114(24):2611-2618.

16. Mészáros I, Mórocz J, Szlávi J, et al. Epidemiology and clinicopathology of aortic dissection. Chest. 2000;117(5):1271-1278.

17. Rashid J, Eisenberg MJ, Topol EJ. Cocaine-induced aortic dissection. Am Heart J. 1996;132(6):1301-1304.

18. Fann JI, Smith JA, Miller DC, et al. Surgical management of aortic dissection during a 30-year period. Circulation. 1995;92(Suppl 9): I113-I121.

19. Fann JI, Sarris GE, Miller DC, et al. Surgical management of acute aortic dissection complicated by stroke. Circulation. 1989;80(3 Pt 1): I257-1263.

20. Fann JI, Sarris GE, Mitchell RS, et al. Treatment of patients with aortic dissection presenting with peripheral vascular complications. Ann Surg. 1990;212(6):705-713.

21. Erbel R, Engberding R, Daniel W, Roelandt J, Visser C, Rennollet H. Echocardiography in diagnosis of aortic dissection. Lancet. 1989; 1(8636):457-461.

22. Ballal RS, Nanda NC, Gatewood R, et al. Usefulness of transesophageal echocardiography in assessment of aortic dissection. Circulation. 1991;84(5):1903-1914.

23. Sommer T, Fehske W, Holzknecht N, et al. Aortic dissection: a comparative study of diagnosis with spiral CT, multiplanar transesophageal echocardiography, and MR imaging. Radiology. 1996;199(2): 347-352.

24. Shiga T, Wajima Z, Apfel CC, Inoue T, Ohe Y. Diagnostic accuracy of transesophageal echocardiography, helical computed tomography, and magnetic resonance imaging for suspected thoracic aortic dissection: systematic review and meta-analysis. Arch Intern Med. 2006;166(13): 1350-1356.

25. Creswell LL, Kouchoukos NT, Cox JL, Rosenbloom M. Coronary artery disease in patients with type A aortic dissection. Ann Thorac Surg. 1995;59(3):585-590.

26. Rizzo RJ, Aranki SF, Aklog L, et al. Rapid noninvasive diagnosis and surgical repair of acute ascending aortic dissection. Improved survival with less angiography. J Thorac Cardiovasc Surg. 1994;108(3): 567-574. 
27. Teman NR, Peterson MD, Russo MJ, et al. Outcomes of patients presenting with acute type A aortic dissection in the setting of prior cardiac surgery: an analysis from the International Registry of Acute Aortic Dissection. Circulation. 2013;128(11 Suppl 1):S180-S185.

28. Feldman M, Shah M, Elefteriades JA. Medical management of acute type A aortic dissection. Ann Thorac Cardiovasc Surg. 2009;15(5):286-293.

29. Kazui T, Komatsu S. [Comparison of long-term results of surgical and nonsurgical therapy in acute aortic dissection]. Nihon Geka Gakkai Zasshi. 1992;93(9):1028-1031. Japanese.

30. Wheat MW Jr, Palmer RF, Bartley TD, Seelman RC. Treatment of dissecting aneurysms of the aorta without surgery. J Thorac Cardiovasc Surg. 1965;50:364-373.

31. David TE, Armstrong S, Ivanov J, Barnard S. Surgery for acute type A aortic dissection. Ann Thorac Surg. 1999;67(6):1999-2001.

32. Moon MR, Sundt TM 3rd, Pasque MK, et al. Does the extent of proximal or distal resection influence outcome for type A dissections? Ann Thorac Surg. 2001;71(4):1244-1249.

33. Elefteriades JA. What operation for acute type A dissection? J Thorac Cardiovasc Surg. 2002;123(2):201-203.

34. Kouchoukos NT. Adjuncts to reduce the incidence of embolic brain injury during operations on the aortic arch. Ann Thorac Surg. 1994;57(1):243-245

35. Anttila V, Pokela M, Kiviluoma K, Mäkiranta M, Hirvonen J, Juvonen T. Is maintained cranial hypothermia the only factor leading to improved outcome after retrograde cerebral perfusion? An experimental study with a chronic porcine model. J Thorac Cardiovasc Surg 2000;119(5):1021-1029.

36. Bavaria JE, Pochettino A. Retrograde cerebral perfusion (RCP) in aortic arch surgery: efficacy and possible mechanisms of brain protection. Semin Thorac Cardiovasc Surg. 1997;9(3):222-232.

37. Okita Y, Minatoya K, Tagusari O, Ando M, Nagatsuka K, Kitamura S. Prospective comparative study of brain protection in total aortic arch replacement: deep hypothermic circulatory arrest with retrograde cerebral perfusion or selective antegrade cerebral perfusion. Ann Thorac Surg. 2001;72(1):72-79.

38. Olinger GN, Schweiger JA, Galbraith TA. Primary repair of acute ascending aortic dissection. Ann Thorac Surg. 1987;44(4):389-393.

39. Gott VL, Pyeritz RE, Magovern GJ Jr, Cameron DE, McKusick VA. Surgical treatment of aneurysms of the ascending aorta in the Marfan syndrome. Results of composite-graft repair in 50 patients. $N$ Engl J Med. 1986;314(17):1070-1074.

40. Kouchoukos NT, Wareing TH, Murphy SF, Perrillo JB. Sixteen-year experience with aortic root replacement. Results of 172 operations. Ann Surg. 1991;214(3):308-318.

41. Eren E, Toker ME, Tunçer A, et al. Surgical management of coronary malperfusion due to type A aortic dissection. J Card Surg. 2007;22(1):2-6.

42. Takahara Y, Sudo Y, Mogi K, Nakayama M, Sakurai M. Total aortic arch grafting for acute type A dissection: analysis of residual false lumen. Ann Thorac Surg. 2002;73(2):450-454.

43. Ando M, Takamoto S, Okita Y, Morota T, Matsukawa R, Kitamura S. Elephant trunk procedure for surgical treatment of aortic dissection. Ann Thorac Surg. 1998;66(1):82-87.

44. Damberg A, Schälte G, Autschbach R, Hoffman A. Safety and pitfalls in frozen elephant trunk implantation. Ann Cardiothorac Surg. 2013;2(5):669-676.

45. Trimarchi S, Nienaber CA, Rampoldi V, et al; International Registry of Acute Aortic Dissection Investigators. Contemporary results of surgery in acute type A aortic dissection: The International Registry of Acute Aortic Dissection experience. J Thorac Cardiovasc Surg. 2005;129(1):112-122.
46. Glower DD, Fann JI, Speier RH, et al. Comparison of medical and surgical therapy for uncomplicated descending aortic dissection. Circulation. 1990;82(Suppl 5):IV39-IV46.

47. Takeshita S, Sakamoto S, Kitada S, Akutsu K, Hashimoto H. Angiotensin-converting enzyme inhibitors reduce long-term aortic events in patients with acute type B aortic dissection. Circ J. 2008; 72(11):1758-1761.

48. Chun AS, Elefteriades JA, Mukherjee SK. Medical treatment for thoracic aortic aneurysm - much more work to be done. Prog Cardiovasc Dis. 2013;56(1):103-108.

49. Coady MA, Rizzo JA, Hammond GL, Kopf GS, Elefteriades JA. Surgical intervention criteria for thoracic aortic aneurysms: a study of growth rates and complications. Ann Thorac Surg. 1999;67(6): 1922-1926.

50. Fattori R, Cao P, De Rango P, et al. Interdisciplinary expert consensus document on management of type B aortic dissection. J Am Coll Cardiol. 2013;61(16):1661-1678.

51. Naughton PA, Garcia-Toca M, Matsumura JS, et al. Complicated acute type B thoracic aortic dissections: endovascular treatment for visceral malperfusion and pseudoaneurysms. Vasc Endovascular Surg. 2011;45(3):219-226.

52. Duson SM, Crawford RS. The role of endografts in the management of type B aortic dissections. Perspect Vasc Surg Endovasc Ther. 2012;24(4):177-183.

53. Ruan ZB, Zhu L, Chen GC, Yin YG. Early and long-term effect of thoracic endovascular aortic repair for Stanford B aortic dissection. Thorac Cardiovasc Surg. October 14, 2013. [Epub ahead of print.]

54. Trimarchi S, Nienaber CA, Rampoldi V, et al. Role and results of surgery in acute type B aortic dissection: insights from the International Registry of Acute Aortic Dissection (IRAD). Circulation. 2006; 114(Suppl 1):I357-I364.

55. Fattori R, Montgomery D, Lovato L, et al. Survival after endovascular therapy in patients with type B aortic dissection: a report from the International Registry of Acute Aortic Dissection (IRAD). JACC Cardiovasc Interv. 2013;6(8):876-882.

56. Estrera AL, Miller CC, Goodrick J, et al. Update on outcomes of acute type B aortic dissection. Ann Thorac Surg. 2007;83(2):S842-S845.

57. Melby SJ, Zierer A, Damiano RJ Jr, Moon MR. Importance of blood pressure control after repair of acute type A aortic dissection: 25-year follow-up in 252 patients. J Clin Hypertens (Greenwich). 2013;15(1):63-68.

58. Shores J, Berger KR, Murphy EA, Pyeritz RE. Progression of aortic dilatation and the benefit of long-term beta-adrenergic blockade in Marfan's syndrome. N Engl J Med. 1994;330(19):1335-1341.

59. Borst HG, Heinemann MK, Stone CD. Surgical Treatment of Aortic Dissection. New York, NY, USA: Churchill Livingstone; 1996.

60. Kirsch M, Soustelle C, Houël R, Hillion ML, Loisance D. Risk factor analysis for proximal and distal reoperations after surgery for acute type A aortic dissection. J Thorac Cardiovasc Surg. 2002;123(2): 318-325.

61. Kouchoukos NT, Marshall WG Jr. Treatment of ascending aortic dissection in the Marfan syndrome. J Card Surg. 1986;1(4):333-346.

62. Yeh CH, Chen MC, Wu YC, Wang YC, Chu JJ, Lin PJ. Risk factors for descending aortic aneurysm formation in medium-term follow-up of patients with type A aortic dissection. Chest. 2003;124(3):989-995.

63. Nienaber CA, Kische S, Akin I, et al. Strategies for subacute/chronic type B aortic dissection: the Investigation Of Stent Grafts in Patients with type B Aortic Dissection (INSTEAD) trial 1-year outcome. J Thorac Cardiovasc Surg. 2010;140(Suppl 6):S101-S108. 


\section{Publish your work in this journal}

Research Reports in Clinical Cardiology is an international, peerreviewed, open access journal publishing original research, reports, editorials, reviews and commentaries on all areas of cardiology in the clinic and laboratory. The manuscript management system is completely online and includes a very quick and fair peer-review system.

Visit http://www.dovepress.com/testimonials.php to read real quotes from published authors. 